\title{
Estimating the direction of lake hydraulic residence in Minnesota's sentinel lakes: implications for
} management

\begin{abstract}
Lake hydraulic residence time is an important lake management variable that is dependent on several factors including: lake volume, watershed size, location within a watershed and climatic variability. The use of the heavy stable isotopes of hydrogen (Deuterium expressed as $\delta \mathrm{D})$ and oxygen $\left(\delta^{18} \mathrm{O}\right)$ can provide hydrologic insight for the development of a Total Maximum Daily Load (TMDL). Constructing a detailed lake water budget can be expensive and challenging. We show that a limited number of stable isotopic lake composition water $\delta \mathrm{D}$ and $\delta^{18} \mathrm{O}$ samples over time can aid in inference of source water input mixing and evaporative processes. Lake water $\delta \mathrm{D}$ and $\delta^{18} \mathrm{O}$ were compared to the isotopic composition of atmospheric water vapor which has a known isotopic concentration at specific latitudes and air temperatures. ${ }^{1,2}$ The deviation in amplitudes of the fractionation of lake water to water vapor was modeled to predict hydraulic residence time for twentyfour lakes throughout Minnesota. Lakes were sampled spring, summer, and fall over a three-year period. Results showed a wide range of hydraulic residence time; variations occurred in annual source water contributions, along with watershed size and connectivity. Ranges of estimated annual hydraulic residence time among individual lakes were as great as 18.8 years and as small as 0.4 years. $\delta \mathrm{D}$ and $\delta^{18} \mathrm{O}$ ratios were plotted in relation to the Meteoric Water Line (MWL) for all study lakes. Annual $\delta \mathrm{D}$ and $\delta^{18} \mathrm{O}$ amplitudes provide directional insight into individual lake water residence times by documenting seasonal variations in a lake's $\delta \mathrm{D}$ and $\delta^{18} \mathrm{O}$ compositions. The use of $\delta \mathrm{D}$ and $\delta^{18} \mathrm{O}$ can offer water quality managers an inexpensive tool to better understand, protect, and remediate lakes and their watersheds.
\end{abstract}

Keywords: isotopes, hydraulic residence time, deuterium, $\delta^{18} \mathrm{O}, \delta \mathrm{D}$
Volume 3 Issue 5 - 2019

\author{
Lee Engel,' Joe Magner² \\ 'Minnesota Pollution Control Agency, USA \\ ${ }^{2}$ Dept of Bioproducts \& Biosystems Engineering, University of \\ Minnesota, USA
}

\begin{abstract}
Correspondence: Joe Magner, Dept of Bioproducts \& Biosystems Engineering, University of Minnesota, 1390 Eckles
\end{abstract} Ave, St. Paul, MN, USA, Email jmagner@umn.edu

Received: September 08, 2019 | Published: September 19. 2019

\section{Introduction}

In the upper Midwest of the North American Continent, lakes are resilient to water quality impairments based on watershed size, land use, morphology, and hydraulic residence time. Watershed size and the amount of runoff entering a lake influence water quality; however, studies $^{3}$ have shown Lake Watershed land use plays a significant role that can protect or impair water quality. Since Lake Basin morphology is relatively constant, we will explore lake hydraulic residence time in more detail. Currently, lake hydraulic residence time is estimated based on apparent input and output; at times, excluding groundwater exchange. Physical measurement presents many challenges in understanding how hydraulic residence time varies depending on seen and unseen water source inputs/outputs. Determining how water cycles through lakes is challenging. The water budget of Midwestern wetlands, streams, and lakes is derived from various sources including precipitation, surface water and/or groundwater. ${ }^{4}$ Depending on the location of the water body and season evaporation can drastically influence water budgets. This paper is not about a comprehensive lake water budget, but relatively simple, coarse method to estimate the direction and possible rate of water flushing in a lake using stable isotopes of water.

Isotopes are atoms of a specific element with a different mass due to a different number of neutrons. Water is composed of oxygen and hydrogen isotopes which occur at different frequencies throughout the hydrologic cycle and are influenced by temperature and latitude. ${ }^{2}$ Over time, water droplets move within the hydrologic cycle and slight changes in the molecular composition can be measured. This hydrologic fractionation creates end-member source waters unique isotopic signatures. ${ }^{5,6}$

The use of stable isotopes has emerged as a vital tool for defining source waters in lakes and predicting hydraulic residence time. The study of isotopes has allowed scientists to determine hydraulic residence time without extremely long data sets. Previously, this technique has been used to quantify the contribution of groundwater, precipitation, and runoff or snow melt to specific bodies of water. ${ }^{1,4,7,8}$ The ratio of stable oxygen $\left(\delta^{18} \mathrm{O}\right)$, and hydrogen $(\delta \mathrm{D})$ in each lake is dependent on a variety of physical processes reflected in the evaporative signature of end-member sources and the final mixing zone. The decoupling of $\delta \mathrm{D}$ and $\delta^{18} \mathrm{O}$ occurs due to fractionation; deuterium evaporates slightly faster than $\delta^{18} \mathrm{O} .{ }^{9}$ the relationship between atmospheric $\delta \mathrm{D}$ and $\delta^{18} \mathrm{O}$ shows a linear correlation which is known as the Meteoric Water Line (MWL). The isotopic enrichments, relative to ocean water, display a linear correlation over the entire range of waters which have not undergone excessive evaporation. ${ }^{9}$ some water bodies show deviations from the MWL, referred to as the "evaporative line," as a result of local climate and water budgets. For a given water sample, fractionation can produce a unique isotopic signature that can offer hydrologic insight. It is difficult, however, to estimate the magnitude of end-member source water contributions 
to the overall water budget of a lake. Lake residence time will be driven by lake morphology, evaporation, and flow into and out of a lake. By identifying a lakes seasonal isotopic signature and its relation to annual oscillations, compared to that of latitudinal water vapor throughout the open water season, it is possible to predict hydraulic residence time. ${ }^{1,10}$ The difference in fractionation between the isotopic water vapor and that of a water body directly correlates to residence time. This difference can be quantified and modeled to give a coarse estimated hydraulic residence time for a specific lake.

\section{Study area/Background}

Water samples were collected to measure $\delta \mathrm{D}$ and $\delta^{18} \mathrm{O}$ from 24lakes throughout the state of Minnesota (Figure 1). These 24lakes were part of the "Sustaining Lakes in a Changing Environment" (SLICE) project, a joint study conducted by the Minnesota Department of Natural Resources and the Minnesota Pollution Control Agency to study how changes in climatic variables influence Minnesota's lakes. ${ }^{11}$ These lakes represent typical lakes found within Minnesota's four Major Land Use Regions (MLUR); Canadian Shield, Transition Forest, Glacial Drift and Northern Forest, and Prairie and Cornbelt. Study lakes range from deep oligotrophic lakes with high groundwater contributions to shallow hypereutrophic, runoff driven lakes. These lakes have very different water budgets and reflect the range of lakes systems found throughout the upper Midwest portion of North America.

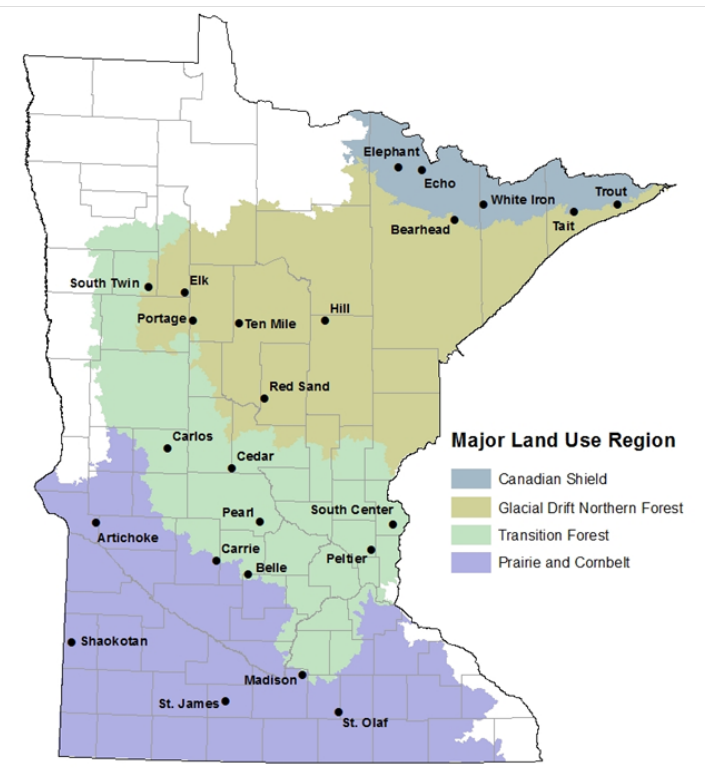

Figure I Map of the 24 study lakes within the four Major Land Use Regions of Minnesota.

\section{Methods}

\section{Sample collection}

From 2008 to 2010 each of the 24lakes were visited during the months of May, July, and October to collect water samples for the analysis of stable isotopes $\delta \mathrm{D}$ and $\delta^{18} \mathrm{O}$. Sampling periods were timed to correspond closely with spring and fall turnover and during midsummer when evaporation is highest. Sampling at these key time periods offers the best opportunity to capture oscillations in $\delta \mathrm{D}$ and $\delta^{18} \mathrm{O}$ for each lake. To ensure that a consistent method of sampling for comparative purposes was used, a composite sample of the top two meters of lake water was taken over the deepest part of the lake basin. An integrated water quality sampler, which is a polyvinyl chloride tube 2 meters in length with an inside diameter of 3.2 centimeters, was used for sample collection. This ensures that the sample is well mixed and representative of the entire lake while eliminating variability from source waters and precipitation events. Surface water sampling protocols were followed from the Minnesota Pollution Control Agency's Standard Operating Procedure for Lake Water Quality Sampling. ${ }^{12}$

\section{Laboratory}

Samples collected were placed in $125 \mathrm{ml}$ plastic water bottles, sealed and sent to the University of Minnesota Biometeorology Lab in the Department of Soil, Water, and Climate under the direction of Dr. Timothy Griffis for analysis. All liquid water samples were analyzed for their isotopic composition using a laser spectroscopy system (Liquid Water Analyzer, DLT-100, Los Gatos Research, Inc) coupled to an autosampler (HT-300A, HTA) for simultaneous measurements of $\delta \mathrm{D}$ and $\delta^{18} \mathrm{O}$.

\section{Modeling/Calculations}

Stable isotope compositions were compared to the isotopic composition of atmospheric water vapor which has a known isotopic concentration at specific latitudes and air temperatures. ${ }^{1,2}$ The deviation in amplitudes of the fractionation of lake water to water vapor was modeled to predict hydraulic residence time for each lake. Estimates for seasonal $\delta^{18} \mathrm{O}$ water vapor values were determined based on seasonal mean minimum and maximum air temperatures using equation $1 .{ }^{13}$

$$
\delta^{18} O_{\text {water vapor }}=(0.521 \pm 0.014) T-(14.96 \pm 0.21)
$$

Where $\mathrm{T}$ is the air temperature in degrees Celsius.

Air temperature data used in Equation 1 were derived from the Minnesota State Climatology Working Group web page (State Climatology Office, MDNR). Minimum and maximum seasonal air temperatures were calculated to represent the expected range of stable isotope compositions of atmospheric water vapor for each lake. Air temperatures were calculated by the location of each lake using ArcMap10.1 for each season; December-February, March-May, JuneAugust, and September-November. The maximum seasonal range of calculated atmospheric stable isotope concentrations was modeled with observed lake water isotopic concentrations to estimate hydraulic residence time.

Hydraulic residence time was estimated using Equation $2^{14}$ by comparing the amplitude of a best-fit curve for precipitation to the amplitude of a similar curve for the water of interest. Seasonal changes in the $\delta^{18} \mathrm{O}$ composition of precipitation at temperate latitudes tend to follow a sinusoidal pattern. This pattern occurs over one year, reflecting the seasonal changes in tropospheric temperature. Measured changes in $\delta^{18} \mathrm{O}$ composition for a stream, lake, pond, soil water, or groundwater are obtained for a given location during different seasons. Mean hydraulic residence can then be calculated if the seasonal waters are considered in steady state and well mixed with an exponential distribution of residence time as:

$$
t=w^{-1}\left[(A / B)^{2}-1\right]^{1 / 2}
$$


Where $\tau$ is the estimated hydraulic residence time, in days, $\omega$ the angular frequency of variation $(2 \pi / 365$ days $)$ or $(0.07172), A$ the input amplitude (precipitation), and $B$ the output amplitude (water of interest).

\section{Results and discussion}

\section{Regional trends}

Throughout the state of Minnesota trends in $\delta \mathrm{D}$ and $\delta^{18} \mathrm{O}$ were similar in all four MLRUs studied (Figures 2\&3). A general transition from lighter to heavier $\delta \mathrm{D}$ and $\delta^{18} \mathrm{O}$ values exists from north to south in Minnesota lakes. The most pronounced difference occurs in the Canadian Shield lakes. This is a result of climatic conditions that are unique to the Canadian Shield MLUR. Weather systems in this region often originate in the Arctic, resulting in light isotopic sources of water vapor as compared to weather systems originating in the Gulf of Mexico. Lake water budgets may also receive higher volumes of light isotopic snow melt runoff than lakes south of the Canadian Shield. A transition to heavier $\delta \mathrm{D}$ and $\delta^{18} \mathrm{O}$ values is evident along the Glacial Drift Northern Forest MLUR. Here $\delta \mathrm{D}$ and $\delta^{18} \mathrm{O}$ values are heavier than Canadian Shield values. The heaviest values of $\delta \mathrm{D}$ and $\delta^{18} \mathrm{O}$ were found in the Transition Forest and Prairie and Corn Belt MLURs. Heavier $\delta \mathrm{D}$ and $\delta^{18} \mathrm{O}$ values are a result of more gulf air precipitation, higher annual evaporation, and higher annual mean temperatures.

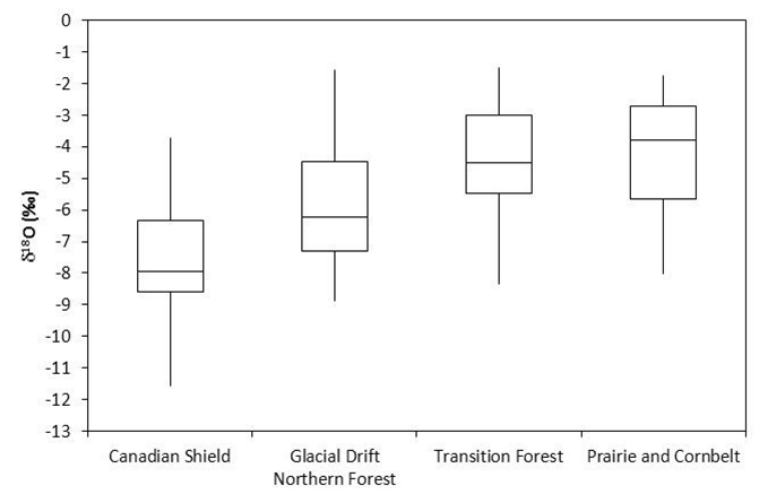

Figure $2 \delta^{18} \mathrm{O}$ values for study lakes within Minnesota's Major Land Use Regions.

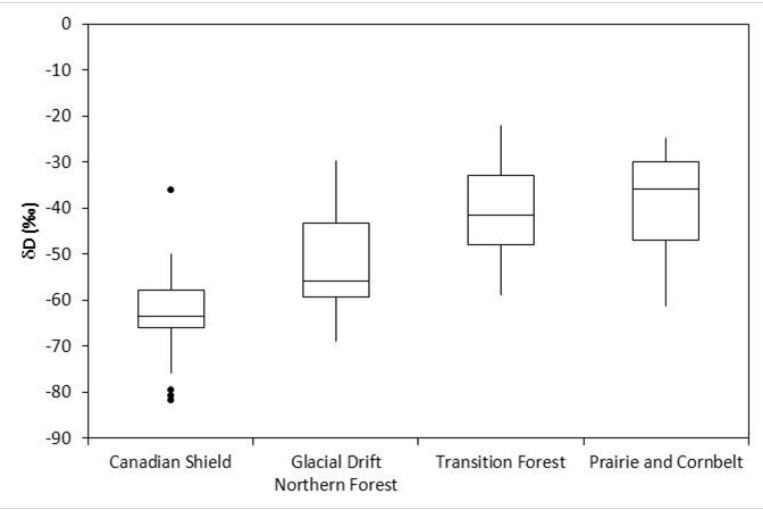

Figure $3 \delta \mathrm{D}$ values for study lakes within Minnesota's Major Land Use Regions.
Study lakes show a strong correlation, $\mathrm{R}^{2}=0.950$, to an evaporative line in Minnesota (Figure 4). Deviations from the MWL are evident at a range of scales. Results were interpreted by state, MLURs, and by individual lake. The further along the evaporative line a lake plots, the more enriched the water is with $\delta^{18} \mathrm{O}$. Canadian Shield lakes plotted low and near the MWL representing waters depleted in heavy oxygen compared to the other three MLURs studied.

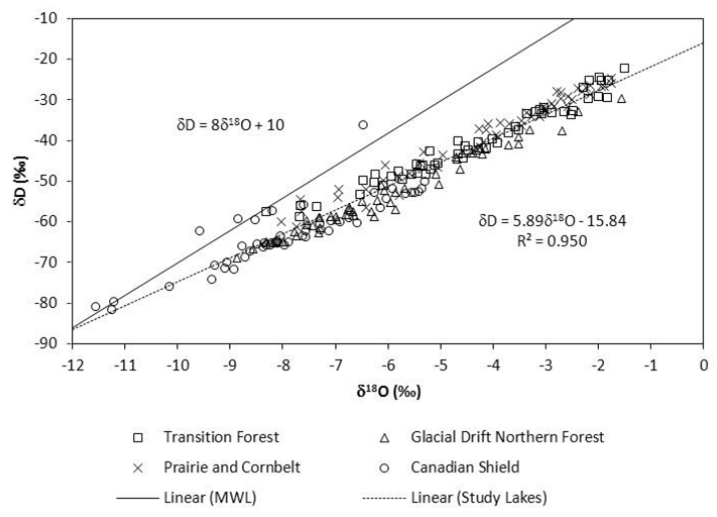

Figure $4 \delta^{18} \mathrm{O}$ vs. $\delta \mathrm{D}$ compared to the MeteoricWater Line across Minnesota's four Major Land Use Regions.

\section{Canadian shield}

Stable isotope $\delta^{18} \mathrm{O}$ values in the Canadian Shield are lower than in the other three MLURs (Figure 2). Measured $\delta^{18} \mathrm{O}$ compositions for each lake in the region are shown in Figure 5. Canadian Shield lakes showed a correlation, $\mathrm{R}^{2}=0.773$, to the evaporative line. This correlation may have been stronger in absence of White Iron Lake, since the lake is a reservoir with a very short residence time and plotted near the MWL. Deep oligotrophic lakes, Bearhead and Trout, had the smallest $\delta^{18} \mathrm{O}$ amplitude in the Canadian Shield MLUR. As a result, these two lakes had the longest calculated hydraulic residence times (Table 1). Echo, Tait, and Elephant lakes are relatively shallow and well connected to their watersheds through many tributaries. Residence times in these lakes were shorter because open channel pathways move water into and out of these lakes (Table 1). White Iron Lake had the shortest residence time of all the Canadian Shield lakes because the lake has a large watershed and is an impoundment on the Kawishiwi River (Table 1). Large volumes of water quickly move through White Iron resulting in a relatively short residence time.

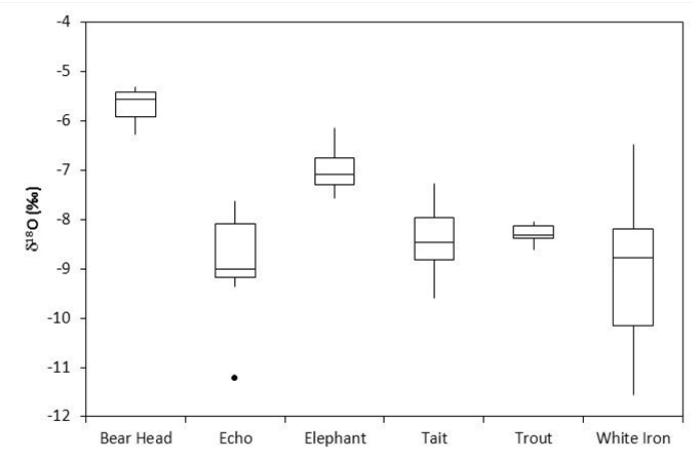

Figure $5 \delta^{18} \mathrm{O}$ values for study lakes within the Canadian Shield MLUR. 
Table I Major Land Use Region's modeled lake residence time ranges based on seasonal minimum and maximum air temperatures

\begin{tabular}{|c|c|c|c|c|c|c|c|c|}
\hline Lake name & Min. 2008 & Max. 2008 & Min. 2009 & Max. 2009 & Min. 2010 & Max. 2010 & Range (Yr) & $\begin{array}{l}\text { Residence time } \\
\text { (Yr) }\end{array}$ \\
\hline \multicolumn{9}{|c|}{ Canadian shield } \\
\hline Bearhead & 2.5 & 2.6 & 3.9 & 3.8 & 17.7 & 17.3 & 15.2 & $2.5-17.7$ \\
\hline Echo & 0.7 & 0.7 & & & 2.2 & 2.1 & 1.5 & $0.7-2.2$ \\
\hline Elephant & 3.2 & 3.3 & 3.2 & 3.2 & 5.6 & 5.5 & 2.4 & $3.2-5.6$ \\
\hline Tait & & & 1.8 & 1.8 & 1.6 & I.7 & 0.2 & I.6-I.8 \\
\hline Trout & 6.9 & 7.7 & 8.7 & 9.3 & 10.5 & 11.8 & 4.9 & $6.9-11.8$ \\
\hline White Iron & I & I & 0.8 & 0.8 & 1.3 & 1.3 & 0.5 & $0.8-1.3$ \\
\hline \multicolumn{9}{|c|}{ Glacial drift northern forest } \\
\hline Elk & 6.2 & 6.4 & 10.9 & 10.5 & 2.9 & 2.9 & 8.1 & $2.9-10.9$ \\
\hline Hill & 7.7 & 8.2 & 2 & 2 & 9.9 & 10.1 & 8.1 & $2.0-10.1$ \\
\hline Portage & 2 & 2 & 3.4 & 3.3 & 2.3 & 2.3 & 1.5 & $2.0-3.4$ \\
\hline Red Sand & 1.3 & 1.4 & 1.4 & 1.3 & 1.6 & 1.7 & 0.4 & I.3-I.7 \\
\hline South Twin & 2.5 & 2.6 & 6.4 & 6.2 & 5.6 & 5.7 & 4 & $2.5-6.4$ \\
\hline Ten Mile & 3.8 & 3.9 & 15.7 & 15.2 & 22.6 & 22.9 & 19.1 & $3.8-22.9$ \\
\hline \multicolumn{9}{|c|}{ Transition forest } \\
\hline Belle & 3.9 & 4.2 & 5.4 & 5.4 & 8.4 & 9 & 5 & $3.9-9.0$ \\
\hline Carlos & 13.6 & 14.2 & 5.1 & 5 & 4.8 & 5.1 & 9.3 & $4.8-14.2$ \\
\hline Cedar & 2.6 & 2.8 & 8.5 & 8.3 & 3.1 & 3.3 & 5.8 & $2.6-8.5$ \\
\hline Pearl & 1.3 & $\mathrm{I} .4$ & 2.4 & 2.4 & 1.8 & 1.9 & I.I & I.3-2.4 \\
\hline Peltier & & & 0.9 & 0.9 & 1.5 & 1.5 & 0.6 & $0.9-1.5$ \\
\hline South Center & 2.7 & 2.9 & 2 & 2 & 6.3 & 6.4 & 4.5 & $2.0-6.4$ \\
\hline \multicolumn{9}{|c|}{ Prairie and cornbelt } \\
\hline Artichoke & 5 & 5.2 & 3.3 & 3.3 & 1.9 & 2.1 & 3.3 & 1.9-5.2 \\
\hline Carrie & 1.3 & 1.4 & 1.4 & I.4 & 2.4 & 2.6 & 1.3 & I.3-2.6 \\
\hline Madison & 2.4 & 2.6 & 2.9 & 3 & 6.7 & 7.1 & 4.7 & $2.4-7.1$ \\
\hline Shaokotan & 1.4 & 1.5 & & & 3.8 & 4.1 & 2.8 & I.4-4.I \\
\hline St James & 1.3 & $\mathrm{I} .4$ & 1.5 & 1.5 & I.I & 1.2 & 0.4 & I.I-I.5 \\
\hline St Olaf & & & 3.2 & 3.2 & 5.7 & 5.9 & 2.7 & $3.2-5.9$ \\
\hline
\end{tabular}

Annual climatic variation also influenced $\delta^{18} \mathrm{O}$ amplitudes and residence times in the Canadian Shield MLUR. In 2010, $\delta^{18} \mathrm{O}$ amplitudes were reduced because of dryer climatic conditions as compared to 2008 and 2009. As a result, residence times increased in most Canadian Shield lakes.

\section{Glacial drift northern forest}

Measured $\delta^{18} \mathrm{O}$ values for each lake in the Glacial Drift Northern Forest MLUR are shown in Figure 6. The isotopic compositions of all lakes sampled in the Glacial Drift Northern Forest MLUR show a strong correlation to the evaporative line, $\mathrm{R}^{2}=0.974$ (Figure 7). In general, a shift towards lighter values of $\delta^{18} \mathrm{O}$ was observed from 2008 to 2010 . This correlates to precipitation patterns in the region which were dryer in 2008 and became progressively wetter by 2010 .

Deep lakes in this MLUR are suspected to have a significant groundwater component to their water budget because of underlying glacial depositional sediment. Conservative $\delta^{18} \mathrm{O}$ amplitudes found in Elk and Ten Mile Lakes provide evidence for the presence of groundwater contributions. As a result, the longest calculated residence times within the Glacial Drift Northern Forest MLUR were in Elk and Ten Mile Lakes (Table 1).

Red Sand Lake was found to have the most enriched water with the widest range of $\delta^{18} \mathrm{O}$ values of all Glacial Drift Northern Forest Lakes. This suggests that the origins of source waters for Red Sand Lake are different than other lakes in this MLUR. Red Sand Lake was the southernmost lake studied in the Glacial Drift Northern Forest MLUR and is likely near the transition between Arctic and Gulf of Mexico derived precipitation. Red Sand Lake's water budget consists of heavy isotopic precipitation from storms originating in the Gulf of Mexico. In contrast the rest of the lakes in this MLUR, located further north, receive precipitation with a lighter isotopic composition from storms originating in the Pacific West and Arctic. 


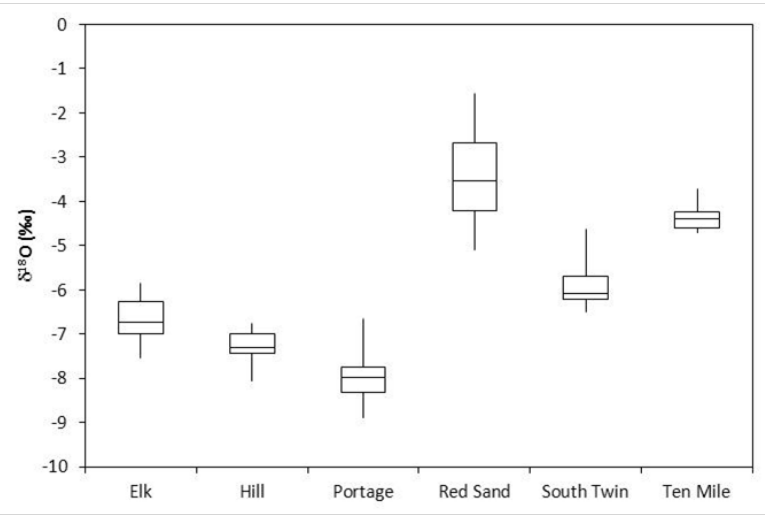

Figure $6 \delta^{18} \mathrm{O}$ values for study lakes within the Glacial Drift Northern Forest MLUR.

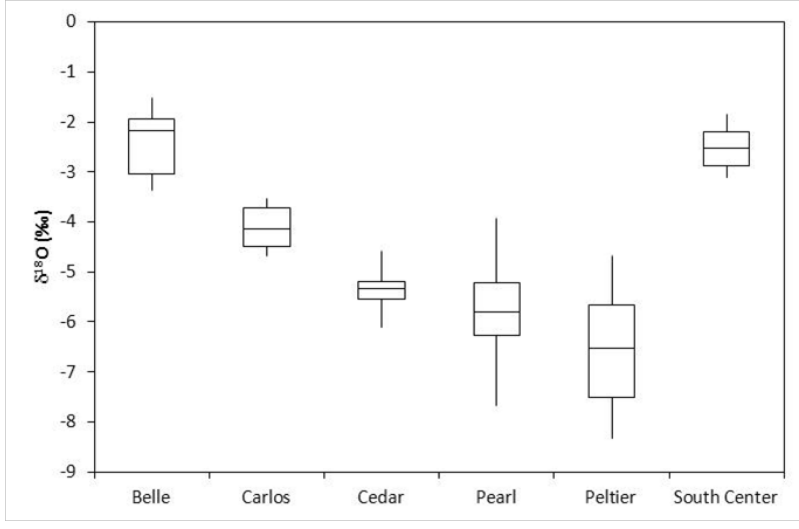

Figure $7 \delta^{18} \mathrm{O}$ values for study lakes within the Transition Forest MLUR.

\section{Transition forest}

Measured $\delta^{18} \mathrm{O}$ values for each lake in the Transition Forest MLUR are shown in Figure 7. The isotopic composition of lakes sampled in this MLUR show a strong correlation to the evaporative line, $\mathrm{R}^{2}=0.961$. In general, a shift towards lighter isotopic values was observed from 2008 to 2010 . Lakes in the western portion of the Transition Forest region received an annual surplus of $20.3-30.5 \mathrm{~cm}$ of precipitation in 2010. Lakes without an outlet, such as Belle, showed a shift to lighter isotopic compositions that was pronounced. This may result in an over-estimate of residence time since lake water was being displaced and lake levels did not stabilize.

Carlos, Cedar, and South Center are all deep lakes; however, their annual water budgets are different. Carlos and South Center are both part of a chain of lakes. During dry years, 2008-2009, discharge from Lake Carlos decreased along with $\delta^{18} \mathrm{O}$ amplitudes, causing residence time to increase (Table 1). South Center Lake has a relatively short residence time for a deep lake due to a complex lakebed and watershed hydrology. During drought years water levels can drop relatively fast due to evaporation and a groundwater sink in the lakebed which increases annual water loss. ${ }^{15}$ Pearl and Peltier Lakes receive large watershed contributions during wet periods, so residence times remain relatively short. Shallow depth and limited lake volume allow for quick flushing of lake water.

\section{Prairie and cornbelt}

Measured $\delta^{18} \mathrm{O}$ values for each lake in the Prairie and Cornbelt MLUR are shown in Figure 8. The isotopic composition of lakes sampled in this MLUR show a strong correlation to the evaporative line $\mathrm{R}^{2}=0.969$. In general, a shift towards lighter values of $\delta^{18} \mathrm{O}$ were observed from 2008 to 2010 . This shift was driven by precipitation patterns in the region. In 2008 and 2009 precipitation was below normal, however 2010 was a wet year and lakes in this MLUR received $33.0-50.8 \mathrm{~cm}$ of precipitation above normal.

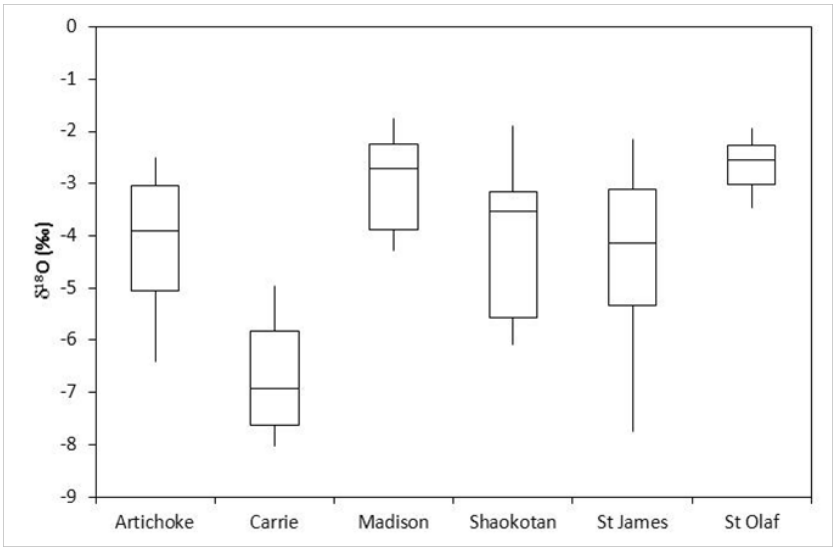

Figure $8 \delta^{18} \mathrm{O}$ values for study lakes within the Prairie and Cornbelt MLUR.

$\delta^{18} \mathrm{O}$ amplitudes responded differently among study lakes in the region. An increase in precipitation, based source waters were routed through these lakes and their watersheds. The presence of lake outlets and the effect of evaporation in shallow lake basins were found to affect $\delta^{18} \mathrm{O}$ amplitudes. This resulted in a shift to lighter $\delta^{18} \mathrm{O}$ values and an increase in residence times in Shaokotan, Madison, and St. Olaf. This was not the case in Artichoke or St. James. Wet years did shift to lighter $\delta^{18} \mathrm{O}$ values, but large evaporative losses to these shallow lakes increased annual $\delta^{18} \mathrm{O}$ amplitudes and decreased residence times. Artichoke's isotopic composition parallels the MWL, suggesting that the lake is influenced by its own local climate and that source waters consist of primarily of precipitation. Carrie Lake's $\delta^{18} \mathrm{O}$ values showed the least variation as a result of above normal precipitation. This is likely because few inflow conduits limit runoff to the lake. This allows precipitation to infiltrate and enter Carrie Lake via groundwater. In contrast, lakes such as St. James have well connected watersheds that quickly transport water through the watershed and lake causing greater variation in $\delta^{18} \mathrm{O}$ amplitudes. ${ }^{16,17}$

\section{Conclusions}

Hydraulic residence time in lakes can be dynamic; changing as a result of variations in annual source water contributions and watershed characteristics. Effects on annual $\delta \mathrm{D}$ and $\delta^{18} \mathrm{O}$ amplitudes and are determined by properties such as lake morphology, watershed size, connectivity, geology, and climate. Stable isotopes $\delta \mathrm{D}$ and $\delta^{18} \mathrm{O}$ provide insight into annual fluctuations of lake water budgets and residence times. By documenting how individual lakes react over time to annual fluctuations, managers can better understand how to protect and remediate lakes and their watersheds.

Using stable isotopes $\delta \mathrm{D}$ and $\delta^{18} \mathrm{O}$, it is possible to identify annual and seasonal variations in source waters and residence time while relating to a watershed's potential for contributing pollutants. Lakes 
with short residence times or large $\delta \mathrm{D}$ and $\delta^{18} \mathrm{O}$ amplitudes tend to be highly connected to their watersheds. If best management practices (BMP) are not used the potential for large pollutant loads to enter the lake may be high. Some lakes have very conservative $\delta \mathrm{D}$ and $\delta^{18} \mathrm{O}$ amplitudes. These lakes typically have a long residence time and are sensitive to even minimal pollutant loading because what enters the lake will reside for some time.

Watershed and lake models use hydraulic residence time to determine how long pollutants may reside in a lake. Typically, residence time is calculated by using lake volume and balancing inflows with outflows of a lake. This method does not represent the true range of residence times that exist because groundwater is usually not considered, and lakes are assumed to be in a steady state which is unlikely with current climatic variability. This is problematic since many protection and restoration plans are based on model results. $\delta \mathrm{D}$ and $\delta^{18} \mathrm{O}$ data can offer a quick less expensive understanding of hydraulic residence time and source water contributions then the physical mass balance approach. Determining source water contributions and how seasonal variations affect $\delta \mathrm{D}$ and $\delta^{18} \mathrm{O}$ compositions is key in determining loading to a lake. Residence time calculations via stable isotopes $\delta \mathrm{D}$ and $\delta^{18} \mathrm{O}$ are made with all water sources to a lake including groundwater. Isotope data can enhance lake water quality models and improve management of lakes and their watersheds.

The method we present should not be used as the end all residence time measurement, but as an estimate of the direction and magnitude of water exchange in a lake. To conduct a thorough lake water budget, evaporation must be constrained more tightly than the method we have used. However, most lake studies lack either the time of financial resources to construct detailed water budgets. We offer this approach as a low-cost method to gain some insight into the possible range of water exchange. Knowledge of lake water exchange can aid lake managers in forecasting lake water quality. Measured changes in $\delta 18 \mathrm{O}$ composition for a stream, lake, pond, soil water, or groundwater are obtained for a given location during different seasons.

\section{Acknowledgements}

This work was funded through the State of Minnesota's Environmental and Natural Resources Trust Fund and the general funding provided to the Department of Natural Resources (DNR) and the Pollution Control Agency.

\section{Conflicts of interest}

The authors declare there are no conflicts of interest.

\section{Funding}

None.

\section{References}

1. Burns DA, McDonnell JJ. Effects of a beaver pond on runoff processes: comparison of two headwater catchments. J Hydro. 1998;205(3-4):248-264.

2. Dansgaard W. Stable Isotopes in Precipitation. Tellus. 1964;16:436-468.

3. Brooks KN, Ffolliott PF, Magner JA. Hydrology and the management of watersheds. $4^{\text {th }}$ edn, Wiley-Blackwell, Hoboken, NJ; 2012. 533 p.

4. Magner J, Alexander S. Drainage and nutrient attenuation in a riparian interception-wetland: southern Minnesota. Environmental Geology. 2008;54(7):1367-1376.

5. Isotope Hydrology. International Atomic Energy Agency. Web. 2009.

6. Craig H. Standard for reporting concentrations of deuterium and oxygen-18 in natural waters. Science. 1961b;133(3467):1833-1834.

7. Fritz P, Fontes J Ch. Handbook of Environmental Isotope Geochemistry. Vol. 1. Elsevier, Amsterdam, Netherlands. 1980; 545 p.

8. Fritz P, Fontes J Ch. Handbook of Environmental Isotope Geochemistry. Vol. 2, Elsevier, Amsterdam, Netherlands. 1986; 557 p.

9. Craig H. Isotopic variations in meteoric waters. Science. 1961a;133(3465):1702-1703.

10. Magner J, Zhang L. Cross River Watershed Hydrologic Adjustment Pre-\&Post-June 2012 Mega-Storm. Journal of Environmental Science and Engineering. 2014;B3:133-141.

11. Valley RD. Sustaining Lakes in a Changing Environment: operational research and management plan. Division of Fish and Wildlife, unpublished DNR report. 2009

12. Minnesota Pollution Control Agency. St. Paul. Standard Operating Procedures (SOP). By Pam Anderson and Matt Lindon; 2009.

13. Yurtsever Y. Worldwide survey of isotopes in precipitation. IAEA report, Vienna. 1975.

14. Maloszewski P, Rauert W, Stichler W, et al. Application of flow models in an alpine catchment area. J Hydro. 1983;66(1-4):319-330.

15. HDR Engineering Inc. Lake to groundwater interaction study. Report to the Chisago Lakes Lake Improvement District. 2008.

16. Pearce AJ, Stewart MK, Sklash MG. Storm runoff generation in humid headwater catchments, 1, Where does the water come from? Water Resources Research. 1986;22(8):1263-1272.

17. Stewart MK, McDonnell JJ. Modeling base flow soil water residence times from deuterium concentrations. Water Resources Research. 1991;27(10):2681-2693. 